\title{
Retrospective Study of Profile of Medico-legal Cases at Basaveshwara Medical College, Chitradurga
}

\author{
Shreedhar N.C $\mathbf{1}$, Chandan.V ${ }^{2}$, Shreekrishna H K $\mathbf{K}^{\mathbf{3}}$ \\ ${ }^{1}$ Associate Professor, ${ }^{2}$ Associate Professor, ${ }^{3}$ Professor, Dept. of Forensic Medicine \& Toxicology, Basaveshwara \\ Medical College \& Hospital, Chitradurga, Karnataka, India
}

\begin{abstract}
Casualty department of any hospital is an important area, because most of the medical emergencies and almost all medico legal cases report first to causality of hospital. The prime duty of doctor is to treat and save the life of patient, however once stabilizedthe same doctor has to carry out exhaustive documentation of medico legal cases. This puts on extra burden on duty Doctor. The present study is carried out with a view to understand the pattern and magnitude of Medico legal cases in this region. Two years retrospective data was collectedbetween 1st January 2018 to 31st December 2019 from the casualty, Basaveshwara Medical College, Chitradurga. Study revealed that Poisoning (40.04\%) constituted majority of medico legal cases followed by road traffic accidents $(31.12 \%)$ with male preponderance (3.32:1); majority of victims were between 21-30 years (32.5\%); large number of victims were urban inhabitants $(57.4 \%)$; most of the cases were from Hindu community (90.4\%); majority of cases (58.9\%) reported to casualty within 1 hour from the time of incidence;maximum number of cases (40.50\%) were reported between 6 pm - 12 am of the day; maximum number of cases was treated on the IPD basis (64.30\%);more number of MLC was reported in month of August (48 cases).
\end{abstract}

Keywords: Medico legal cases, Road Traffic Accidents, Assault, Poisoning.

\section{Introduction}

Medico legal cases (MLC) are essential component of medical practice and comprise most important constituent of emergencies. ${ }^{1}$ Medico-legal case can be defined as a case of injury or ailment, etc. in which investigation by the law enforcing agencies are essential to fix the responsibility regarding the causation of the said injury or ailment. In simple language it is a medical case with legal implications for the attending doctor where the attending doctor, after eliciting history and examining the patient, thinks that some investigation

\author{
Corresponding Author: \\ Dr. Shreekrishna H K \\ Professor, Dept. of Forensic Medicine \& Toxicology \\ Basaveshwara Medical College \& \\ Hospital,Chitradurga, Karnataka, Indi \\ Phone No-7200278293 \\ Email-krishnashree61@yahoo.co
}

by law enforcement agencies is essential. ${ }^{2}$ Common medico-legal cases include alleged cases of assault, road traffic accidents, burns, poisoning, snake bite, insect bite, industrial accidents, alcoholic intoxications etc.

All the medico-legal cases are registered in casualty. Casualty department is very crucial for any hospital as all the medical and surgical emergencies first report there. Further it serves as an outpatient department after the routine outpatient department hours.

Medico-legal case is an integral part of medical practice that is frequently encountered by medical officers working in emergency department. For such patients, not only treatment, but exhaustive documentation is also mandatory. The on-duty doctor in the casualty department has to first stabilize the patient of any emergency. He is also duty bound to register a particular case as a medico-legal case whenever indicated and has 
Medico-legal Update, October-December 2021, Vol.21, No. $4 \mathbf{3 4 9}$

to examine thesame. In the present study an attempt is made to know the workload of medico-legal cases and their pattern.

\section{Aim and Objectives}

1. To study the pattern of MLC Cases, with regard to various criteria like age, sex, manner, hospital outcome, etc.

2. To give suggestions for improving quality of Medico-legal work in casualty.

3. To analyse the data and use it for betterment of patient care in the Emergency Department.

4. To make recommendations to administrative authorities according to outcome of study.

\section{Material and Methods}

This is a record based retrospective study of medicolegal cases registered in MLC register in casualty of Basaveshwara Medical College, Chitradurga from January 2018 to December 2019. Related data like, age and sex of cases, cause \& manner of injury, time of injury, time period between injury and reporting to casualty, hospital stay \& outcome, months and season concern in arrival of medico-legal cases in casualty was collected from medico-legal register. The collected data wasanalysed and presented in tables, graphs and pie charts by using various parameters and compared with other studies.

Inclusion criteria : All the medico-legal cases registered during 1st January 2018 to 31 st December 2019 in the MCL record book were included.

Exclusion criteria: Cases found non medico-legal and those with incomplete entry were excluded.

\section{Observations and Results}

Total number of medico-legal cases included in the study was 437 from the record of medico-legal cases from 1st January 2018 to 31 st December 2019. Out of 437 cases, $336(76.9 \%)$ were males and 101 (23.1\%) were females. In the present study, maximum numbers of cases (32.5\%) were from the age group of 21-30 years followed by $20.8 \%$ from the age group of $31-40$ years. The individuals of geriatric age group were also involved in the medico-legal cases. (Table 1)

Taking religion into consideration, most of the cases were from Hindu community (90.4\%), followed by Muslims in $7.2 \%$ cases and Christians were $1.4 \%$. Maximum $(251,57.4 \%)$ cases were from urban area and rest of the cases i.e. $186(42.6 \%)$ were from rural areas.

More number of cases (40.50\%)was reported between $6 \mathrm{pm}-12 \mathrm{am}$, followed by $32.50 \%$ of the cases reported between 12 pm - 6 pm, least number of cases reported between 12 am - 6 am. (Table. 2)Majority of cases $(58.9 \%)$ reported to casualty within 1 hour from the time of incidence, $25.70 \%$ cases reported within 1-4 hours, $11.30 \%$ cases reported within 4-12 hours, whereas $4.1 \%$ cases reported after 12 hours of incidence. (Fig 1)

Our study shows that poisoning was the predominant cause $(40.04 \%)$, followed by road traffic accidents $(31.12 \%)$ and snake bites (9.61\%). Maximum number of MLC was reported in month of August (48 cases), followed by September (45 cases). Least numbers of cases were reported in February (19 cases). Maximum number of RTA cases was noted in months of March \& April (39 cases). Maximum number of poisoning cases was noted in August \& September (55 cases).(Table 3) Alleged manner of incidence was accidental in 52.40\% cases, suicidal in $41.41 \%$ cases, homicidal in $5.03 \%$ cases,natural in $0.69 \%$ cases and in $0.46 \%$ of the cases manner of incident was not known. (Fig. 2)

Maximum number of cases was treated on the IPD basis (64.30\%). $32.72 \%$ of the cases were treated on OPD basis while (2.97\%) were brought dead. (Table 4) Out of 424 living cases brought to casualty, maximum number of cases $(81.84 \%)$ were discharged after completion of treatment, $12.03 \%$ cases were referred to higher centres for further treatment and $5.90 \%$ cases died during the course of treatment while 1 patient absconded from the casualty. (Table 5) 
Table 1: Distribution of cases according to age groups and sex

\begin{tabular}{|c|c|c|c|}
\hline Age group (years) & Males & Females & Total \\
\hline $0-10$ & 7 & 4 & $11(2.5 \%)$ \\
\hline $11-20$ & 49 & 18 & $67(15.3 \%)$ \\
\hline $21-30$ & 113 & 29 & $142(32.5 \%)$ \\
\hline $31-40$ & 68 & 23 & $91(20.8 \%)$ \\
\hline $41-50$ & 45 & 13 & $58(13.3 \%)$ \\
\hline $51-60$ & 29 & 8 & $37(8.5 \%)$ \\
\hline $61-70$ & 19 & 5 & $24(5.5 \%)$ \\
\hline $71-80$ & 4 & 1 & $5(1.1 \%)$ \\
\hline $81-90$ & 2 & 0 & $2(0.4 \%) \mathrm{m}$ \\
\hline Total & $336(76.9 \%)$ & $101(23.1 \%)$ & $437(100 \%)$ \\
\hline
\end{tabular}

Table 2 :Distribution of cases according to time of incident

\begin{tabular}{|c|c|c|}
\hline Time of incident & No. of cases & Percentage \\
\hline $12 \mathrm{am}-6 \mathrm{am}$ & 47 & $10.75 \%$ \\
\hline $6 \mathrm{am}-12 \mathrm{pm}$ & 71 & $32.50 \%$ \\
\hline $12 \mathrm{pm}-6 \mathrm{pm}$ & 142 & $40.50 \%$ \\
\hline $6 \mathrm{pm}-12 \mathrm{am}$ & 177 & $100 \%$ \\
\hline
\end{tabular}




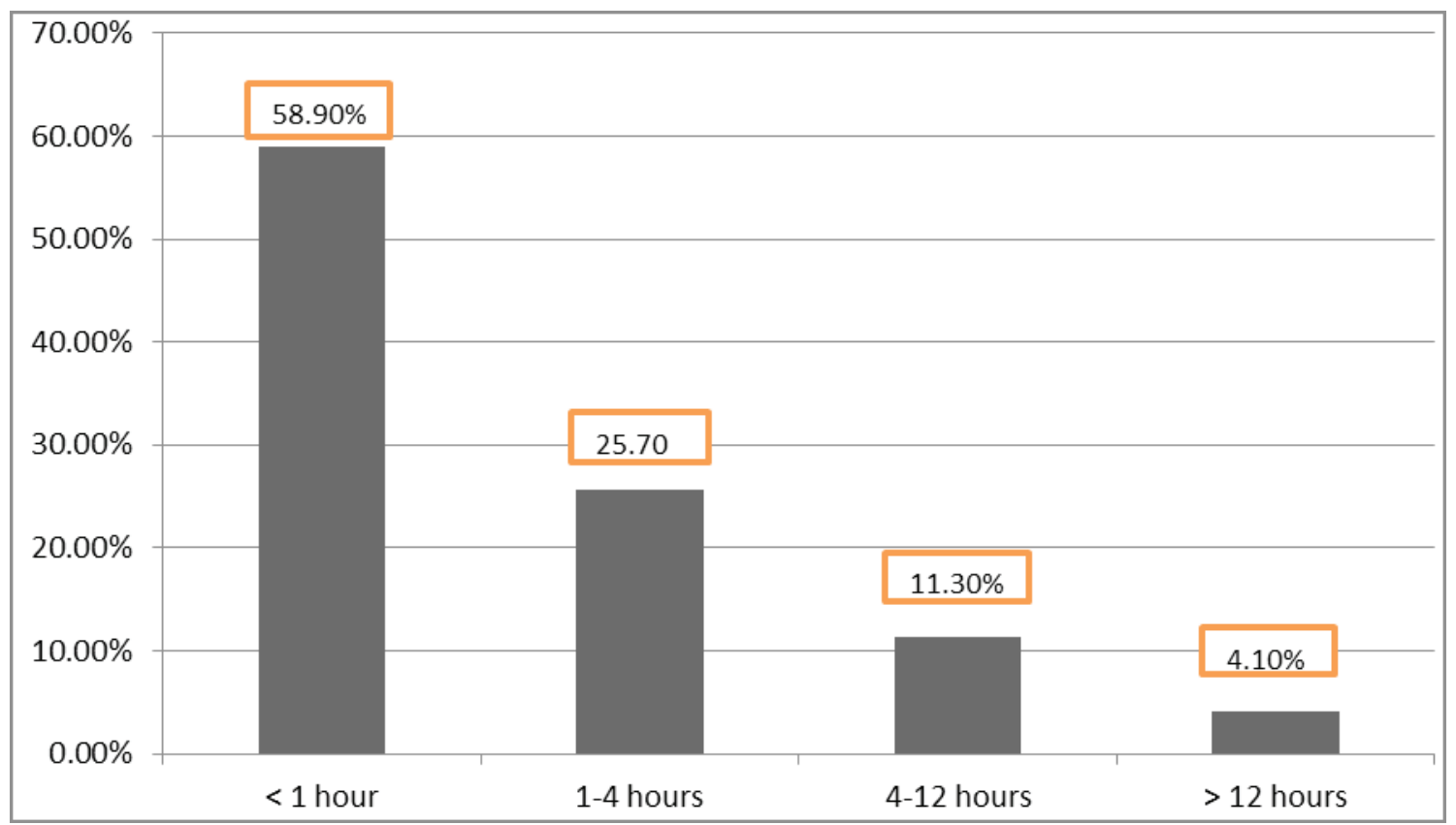

Figure 1: Time period between incidence and reporting to casualty

Table 3: Monthly distribution of different categories of MLC

\begin{tabular}{|c|c|c|c|c|c|c|c|c|c|c|c|c|c|c|}
\hline Type of MLC & Jan & Feb & Mar & Apr & May & June & July & Aug & Sep & Oct & Nov & Dec & Total & $\%$ \\
\hline $\begin{array}{l}\text { Road traffic } \\
\text { accidents }\end{array}$ & 12 & 6 & 18 & 21 & 11 & 8 & 10 & 5 & 9 & 12 & 13 & 11 & 136 & $31.12 \%$ \\
\hline Railway injury & 1 & 0 & 1 & 0 & 0 & 0 & 0 & 0 & 0 & 0 & 0 & 0 & 2 & $0.46 \%$ \\
\hline Industrial injury & 0 & 0 & 0 & 1 & 0 & 0 & 0 & 0 & 1 & 1 & 0 & 0 & 3 & $0.69 \%$ \\
\hline Poisoning & 6 & 9 & 7 & 10 & 11 & 15 & 19 & 27 & 28 & 20 & 13 & 10 & 175 & $40.04 \%$ \\
\hline Assault & 2 & 1 & 3 & 2 & 5 & 0 & 2 & 3 & 1 & 2 & 0 & 0 & 21 & $4.80 \%$ \\
\hline Fall from height & 1 & 0 & 2 & 1 & 0 & 3 & 0 & 2 & 0 & 0 & 0 & 2 & 11 & $2.51 \%$ \\
\hline Burns & 0 & 1 & 2 & 4 & 1 & 0 & 0 & 0 & 0 & 1 & 0 & 0 & 9 & $2.06 \%$ \\
\hline Snake bite & 0 & 1 & 2 & 1 & 5 & 8 & 7 & 9 & 3 & 3 & 2 & 1 & 42 & $9.61 \%$ \\
\hline $\begin{array}{l}\text { Bee sting \& } \\
\text { insect bite }\end{array}$ & 1 & 0 & 0 & 2 & 3 & 2 & 1 & 0 & 0 & 1 & 1 & 0 & 11 & $2.51 \%$ \\
\hline Electric injury & 1 & 0 & 2 & 0 & 0 & 1 & 0 & 0 & 1 & 0 & 0 & 0 & 5 & $1.14 \%$ \\
\hline Near drowning & 0 & 0 & 0 & 0 & 0 & 0 & 0 & 1 & 0 & 1 & 0 & 0 & 2 & $0.46 \%$ \\
\hline Sexual assault & 1 & 0 & 0 & 0 & 0 & 0 & 0 & 0 & 0 & 0 & 0 & 0 & 1 & $0.23 \%$ \\
\hline Gunshot injury & 0 & 0 & 0 & 0 & 0 & 0 & 0 & 0 & 0 & 0 & 1 & 0 & 1 & $0.23 \%$ \\
\hline Injury by animal & 0 & 1 & 0 & 0 & 0 & 0 & 0 & 1 & 2 & 0 & 0 & 1 & 5 & $1.14 \%$ \\
\hline Brought dead & 1 & 0 & 0 & 1 & 3 & 0 & 1 & 0 & 0 & 2 & 2 & 3 & 13 & $2.97 \%$ \\
\hline Total & 26 & 19 & 37 & 43 & 39 & 37 & 40 & 48 & 45 & 43 & 32 & 28 & 437 & $100 \%$ \\
\hline
\end{tabular}


Fig. 2: Alleged manner of incidence

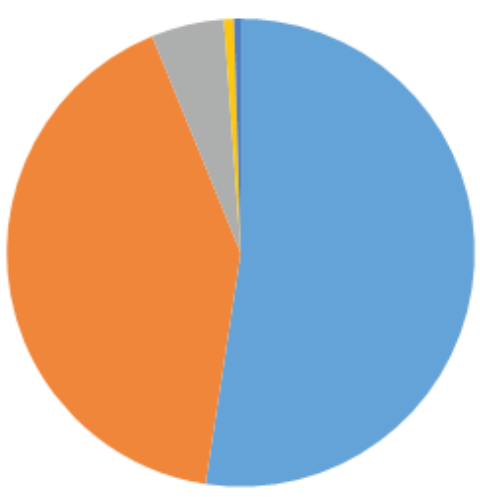

Accidental - 52.40\%

Suicidal - 41.41\%

Homicidal - 5.03\%

Natural - 0.69\%

Not known - $0.46 \%$

Table 4: Distribution of cases on the basis of OPD or IPD treatment

\begin{tabular}{|c|c|c|}
\hline Treated as & No. of cases & Percentage \\
\hline Out patient & 143 & $32.72 \%$ \\
\hline In patient & 281 & $64.30 \%$ \\
\hline Brought dead & 13 & $2.97 \%$ \\
\hline Total & 437 & $100 \%$ \\
\hline
\end{tabular}

Table 5: Distribution of cases according to disposal

\begin{tabular}{|c|c|c|}
\hline Disposal of the MLC cases & No. of cases & Percentage \\
\hline Discharged & 347 & $12.03 \%$ \\
\hline Referred & 51 & $5.90 \%$ \\
\hline Dead & 25 & $0.23 \%$ \\
\hline Absconded & 1 & $100 \%$ \\
\hline Total & 424 & \\
\hline
\end{tabular}

\section{Discussion}

Total number of medico-legal cases reported during 2 years period was 437, of which majority (336, $76.9 \%$ ) were males. Similar findings were reported by Brahmankar et al, Garg et al, Malik et al, Haridas et al, and Hussaini et al. ${ }^{3-7}$ This is because males are more exposed to outdoor activities, social activities as well as disputes in family matters. Also male by nature indulge in more violent activities as compared to female. Like other studies, ${ }^{3-9}$ present study has shown the age group of 21-30 years as most commonly involved age group in medico-legal cases, followed by the age group of 31-40 years. This can be explained by the fact that they were more active, economically productive, violent and arrogant by nature also mostly involved in outdoor 
household activities. They were more vulnerable to the fast changing social trend and culture as they are mentally a bit immature with little experience of life. Most of them are married during this period and are exposed to a new married life with family and social adjustments.

In our study victims of Hindu religion were maximum (90.4\%) because Chitradurga region has a predominantly Hindu population. It was observed that urban victims constituted $57.4 \%$ and the rural victims were $42.6 \%$. Similar findings were observed by Hussaini $\mathrm{SN}$ et aland JitendraTomar et al. ${ }^{7,10}$ Our Medical College is situated in city hence patients from urban area are more than the patients residing in rural area.

Maximum incidence of MLCs took place in between 12 p.m. to 12 a.m. because in this time of day people are maximally involved into their activities. This is in consistence with the study byGarg et al, Gupta et al and Trangadia MM et al. ${ }^{4,9,11}$ As the day progress frustration of person increased, the temperature and humidity level of environment was also high during this time period of day. Minimum incidences of MLCs (10.75\%) were seen in between 12 a.m. to 6 a.m. because people usually remain asleep.

In our study it was observed that majority of the medico-legal cases $(58.9 \%)$ reported to casualty within 1 hour of the incidence, followed by $25.70 \%$ of the victims between 1- 4 hours of the incidence. Our findings are consistent with study conducted byJitendraTomar et al, Yadav A et al and Siddappa SC et al. ${ }^{10,12,13}$ It can be explained by the fact that urban population have tertiary care hospital in their close vicinity and also have more health awareness as compared to rural population.

It was observed that maximum cases were of poisoning (40.04\%) in consistence with study by Yadav et al and KarSM et al in which poisoning cases having highest incidence $(36.9 \%) \cdot{ }^{13,14}$ It is because our hospital caters most of the rural population of our district where most of the households are involved in agriculture work, so the poisons are easily available. Haridas et al,JitendraTomar et al,Siddappa et al,Saxena et al and Dileep Kumar $\mathrm{R}$ et $\mathrm{al}^{6,10,12,15,16}$ observed in their studies that maximum cases reported to casualty were of RTA which differ from our study. In our study $31.12 \%$ of the cases were due to RTA which can be explained by the fact that we passing through a major socio-demographic, epidemiological \& technological transition. India has witnessed rapid urbanization, motorization, industrialization and migration of people. The motorizations of India have resulted in greater number of deaths and injuries. This is also due to absence of safety policies, poor road conditions \& ignorance regarding the law.

In our study maximum number of cases was noted in the month of August and September. It could be due to the sudden increase in the cases of poisoning and snake bites. This result was consistence with the study of Garg et al, Hussaini et al and Trangadia et al ${ }^{4,7,11}$. This could be due to the increased farming activity in rainy season. Majority of farming activity like spraying of insecticide is done in monsoon season. So the chances of accidental as well as suicidal poisoning are more. Incidence of bite by poisonous animals was also increased in rainy season. Cases of RTA have shown peak in the month of March \& April which is not consistent with the study by Dhillonet al ${ }^{17}$ where there was peak of RTA in January, February, May and June. In the months of March \& April, more number of burns cases was noted in the present study because in summer season chances of accidental burns are more.

In the present study, majority of the medico-legal cases were accidental $(52.40 \%)$ in nature, followed by suicidal $(41.41 \%)$ and then homicidal in $5.03 \%$ of cases,natural in $0.69 \%$ cases and in $0.46 \%$ of cases manner of incident was not known. Our study is consistent with JitendraTomar et al and Siddappa SC et $\mathrm{al}^{10,12}$. It is inconsistent with study conducted by Yadav $\mathrm{A}$ et $\mathrm{al}^{13}$ where assault cases $(39.6 \%)$ were almost equal to accidental cases $(38.1 \%)$.

In our study most of the cases were treated in IPD $(64.30 \%)$ and $32.72 \%$ of the cases had minor injuries, so they did not required admission and were dealt at the 
354 Medico-legal Update, October-December 2021, Vol.21, No. 4

OPD level. Out of 424 living cases brought to casualty, maximum numbers of cases were discharged after completion of treatment (347 cases, 81.84\%), 51 cases $(12.03 \%)$ were referred to higher centres for further treatment and 25 cases $(5.90 \%)$ died during the course of treatment, while 1 patient absconded from the casualty. The present study is consistent with the study conducted by Trangadia MM et al. ${ }^{11}$

\section{Conclusions \& Recommendations}

The casualty department plays a vital role in treating in emergencies as well as handling of legal implications of the cases, this puts a lot of burden on casualty department and on first contact doctor, most of time they are MBBS only. The doctor those are involved in handling medico legal cases need to be more trained. Casualties of Medical Colleges have lot of exposure of medico legal cases, so hospital has the need for round the clock availability of Forensic experts.

Males and young age group are most commonly involved group in Medico-legal cases. Proper counselling for developing positive attitude and controlling the aggression in youth have to be promoted. Strategies for alcohol control should be stringent.

Poisoning cases have a high incidence in our population. Emergency department should be well equipped with all the antidotes and the drugs which are used for the treatment of agricultural poisons. Awareness regarding role and functions of Poisons Information Centre should be created among the medical staff in the casualty. Accidents and Injuries can be prevented by proper education, awareness and training of safety standards which are required to be implemented strictly.

Although in the presence of substantial evidence, emerging medico legal cases are neglected in most of the developing countries. The magnitude of problem needs to be addressed and comprehensive approach for preventive strategies ought to be developed by public health officials. Further research can be conducted to find out incidence, aetiology and outcome of these medico legal issues for concerned sections of the society.
Funding: No funding sources

Conflict of Interest: None declared

Ethical Approval: The study was approved by the Institutional Ethics Committee

\section{References}

1. Singh P, Verma SK. Profile of Medico legal Cases Admitted at a Newly Established Rural Medical College Hospital of Central India. Medico-Legal Update. 2015;15(1):111-115. doi: 10.5958/09741283.2015.00026.2

2. Kumar A. Evidentiary value of medical evidence in Indian courts. J Indian Acad Forensic Med. 2007;24(4):136.

3. Brahmankar TR, Sharma SK. A record based study of frequency and pattern of medico-legal cases reported at a tertiary care hospital in Miraj. Int J Community Med Public Health 2017;4:1348-52.

4. Garg V, Verma SK. Profile of medico legal cases at Adesh institute of medical Sciences and research Bhatinda Punjab. J Indian Acad Forensic Med. 2010;32(2):150-2.

5. Malik Y, Chawla R, Sharma G, Malik P, Singh $\mathrm{R}$, Tripathi A. Profile of medico legal cases in causality of a rural medical college of Hariyana. J Indian Acad Forensic Med. 2013;35(4):367-8.

6. Haridas SV, Pawale DA. A retrospective study of pattern of clinical Medico-legal cases registered at tertiary health care centre in Kolhapur district. J Forensic MedSci Law. 2014;23(2):1-5.

7. Hussaini SN, Kulkarni CS, Batra AK. Profile of Medico-legal cases coming to casualty of Government Medical College Akola. J Forensic Med Sci Law. 2013;22(2):1-6.

8. Benomran FA. The medico-legal science in dubai:2002-2007. Journal of Forensic and Legal Medicine 2009; 16: 332-7.

9. Gupta B, Singh S, Singh H, Sharma RK. A one Year Profile of Medico-legal Cases at Tertiary Care Hospital in Western Uttar Pradesh. MedicoLegal Update 2012; 12(2):30-5.

10. JitendraTomar, AbhishekVarun, Manish Nigam, Pradeep K. Mishra, PankajVerma. Profile of medicolegal cases in the Casualty of SAMC and PGI, Indore. Indian Journal of Forensic and Community Medicine; July-September 2017;4(3):171-175 
11. Trangadia MM, Mehta RA, Rada NH, Gupta BD. Profile of medico-legal cases in tertiary care hospital in Jamnagar, Gujarat: Retrospective study of one year. J Res Med Den Sci 2014;2(4):57-62.

12. Siddappa SC, Datta A. A Study Pattern of Medicolegal Cases Treated at a Tertiary Care Hospital in Central Karnataka. Indian Journal of Forensic and Community Medicine, 2015;2(4):193-197.

13. Yadav A, Singh NK. Pattern of Medico-legal Cases in rural Area of Faridabad, Haryana. J Indian Acad. Forensic Med.2013;35(1):60-2.

14. Kar SM, TimsinhaS, AgrawalP. AnEpidemiological study of Organophosphorus Poisoning at Manipal Teaching Hospital, Pokhara, Nepal. J Indian Acad Forensic Med 2010; 32(2): 108-09.
15. Saxena A, Kumar V, Chaudhary SR, Singh J, Awasthi S. Pattern of Medico-legal Cases in the Casualty Department of A Teaching Hospital, Bareilly, UttarPradesh. J Indian Acad Forensic Med. 2015;37(4):33840.

16. Dileep Kumar R, Siddaramanna T C, Shailesh V Parate, Hemanthraj M N.Retrospective Study of Profile of Medico-legal Cases in Tumkur Region, Karnataka. International Journal of Biomedical and Advance Research 2015; 6(04):339-340.

17. Dhillon S, Sekhon HS. Pattern and distribution of injuries in fatal road traffic accidents in Shimla. Medico-legal Update 2007; 7(4):115-8. 